\title{
UNIVERSALS AND THE DIACHRONIC LIFE CYCLE OF LANGUAGES
}

JAMES R. HURFORD

\subsection{Acquisition Is Only Half of the Story}

A prevalent form of explanation for universals of language (expounded in many of Chomsky's works, e.g., Chomsky, 1965) links linguists' theoretical descriptions of languages with language acquisition. From my own perspective, this generative approach is only partially adequate, as the title of this section suggests. The next paragraph below sketches a typical way in which generative linguists steer a tactical course between what is significantly common to all languages (thus potentially hypothesized to be linked to some bias in language acquisition) and what is idiosyncratic to particular languages (implicitly because of some other, usually unspecified, processes).

Linguists are interested in the common framework on which all languages are built, that is, in universals of language; they also have to cope with the great diversity of languages. General scientific methodology dictates that the description of each language should be as elegant and economical as possible, consistent with the facts. This pushes the linguist to formulate general synchronic rules and principles as the "core grammar" of a language, with lists of idiosyncratic facts treated as peripheral. The lexicon, a store of arbitrary sound-meaning links, is the most obvious "peripheral" component. Somewhere between general principles applying to the core grammars of all languages and the idiosyncratic lexicon are the values of parameters fixed during language acquisition (Chomsky, 1981). Fixing a parameter amounts to making a generalization over, for example, head-dependent constituent order, or whether the language permits null subjects, or the precise barriers to syntactic movement rules. Languages vary along these parameters, and this variation, along with the arbitrary facts of the lexicon, contributes to the diversity of languages. 
Language is not totally innate; what is learned, be it arbitrary lexical formmeaning mappings or the values of parameters, is what makes the diversity of languages. If language were totally innate, there would be linguistic universals only in the trivial sense that there would be a single truly universal language, the only one that humans could possibly speak. Two correspondences have emerged in linguistic theorizing over the past 50 years: associating universals with what is innate and diversity with what is learned. The associations are made more subtle by extending the scope of the term universal not only to what languages must be like (i.e., what is innate and must be part of an acquired grammar), but also to constraints on what languages can be like (i.e., what can be acquired).

Already implicit here, and acceptable as part of the theory of language, is the idea that universal facts about languages can be explained by innate constraints on language acquisition, either absolute as principles or less absolute as parameters. And the obviously correct definition of acquisition is that it requires some input. Not even the most ardent nativist would claim that a language grows in a child wholly without input. And, within the innate constraints, the language acquired is determined by the input. Children arrive at some compromise between their innate template for language and the data bombarding them. They make generalizations over the data where the data fit nicely with innate biases, and where they don't, if the data is salient or frequent enough, they just memorize idiosyncratic facts. Given this picture, and accepting the idea of some innate biases (of course all learning is biased-there is no such thing as unbiased learning), it is easy to see how some universal patterns emerge in languages, but it is much less easy to see where the diversity comes from. In short, what keeps languages so diverse among themselves, and what keeps each language so full of stuff that has to be learned? Why should there ever be, in the data to which the child is exposed, any salient or frequent examples that just require memorizing?

To highlight this question, consider the ubiquitous presence of irregularity in languages. In the everyday, nontechnical sense of universal, irregularities are universal in languages. Only artificial languages, like Esperanto, are mostly lacking in irregularities (though even the original Esperanto had a few irregularities). It seems a natural prediction that once Esperanto has been transmitted culturally in a sizeable population for a few centuries, it, too, will evolve more irregularities. Now, an irregularity, by definition, cannot be the outcome of an innate bias. The innate language acquisition device doesn't say, "When you acquire this verb, whatever you do, make sure it doesn't conform to any of the general rules in your language." We know that children overregularize irregular verbs, saying "comed" and "taked," until the data make them change their minds, and they learn the irregular forms. What keeps languages somewhat irregular? Why don't the undoubted innate biases of children toward regularity overcome the irregularities? Because the irregularities 


\section{Language Universals}

are too persistent and salient in the input data. But why? Innate dispositions cannot provide the answer.

Irregularities are doubtless bona fide parts of any language, as second-language learners know to their pain. One may take a dismissive attitude and pronounce that they are "not interesting" because they do not shed light on the nature of the innate language-learning bias, the faculty of language in the narrow sense, "FLN" (Hauser, Chomsky, \& Fitch, 2002). True, they don't, except to show the limitations of the innate learning bias as an explanans for all the parts of any language. Defining the goal of linguistics as just the discovery of the innate learning biases is not the only choice. Many researchers come to the subject through exposure to individual languages, and with a curiosity about what forms them, warts and all. The project to explain what makes whole languages the way they are goes beyond even consideration of the faculty of language in the broad sense, "FLB" (Hauser et al., 2002), because "each actual 'language' will incorporate a periphery of borrowings, historical residues, inventions, and so on” (Chomsky, 1981, p. 8). Chomsky's discussion $(1981,1986)$ of the motivation for a study of the individual psychological aspects of language is useful, but he is dismissive of any wider consideration of such historical and social factors "which we can hardly expect to-and indeed would not want to-incorporate within a principled theory of UG." (1981, p. 8) I do not share his pessimism about saying something systematic about the social and historical factors affecting languages. Indeed, unless one has a clear picture of what the historical and social influences on the formation of languages may be, it will be hard to reliably isolate the remaining individual psychological contribution, Universal Grammar (UG).

Irregularities are preserved by being repeated often enough in each generation to force the learner to deviate from otherwise regular patterns. Irregularities are stored both privately inside the heads of speakers who have memorized them and publicly outside in the community where their frequent rehearsal ensures that they don't go away in the next generation. This highlights a fact obvious in itself, but oddly not built into much theorizing about the nature of language. Languages are socially transmitted. Children acquire grammars not by telepathic access to the grammars in their parents' heads but by exposure to utterances in context. Thus languages, like egg-chicken life forms, exist in two distinct life phases, which we can conveniently identify as competence and performance.

The distinction between competence and performance is indispensable to any account of the nature of language. Performance is the externally observable behaviour of speakers, mostly displaying the regularities of their language, but also inevitably including occasional disturbances, such as hesitations and false starts. Competence is whatever a speaker has in his/her head that determines the form-meaning pairs of the language the person speaks. Opponents of the 
competence/performance distinction should not assume that competence necessarily comes with all of the theoretical baggage accumulated by generative linguistics in the past decades. Some of this accumulation may be correct, but it is not itself part of the definition of competence. We may disagree about the details, some perhaps preferring a list of constructions, others a richly structured lexicon plus the Merge operation, and yet others a set of weighted connections between arrays of nodes encoding meanings and forms. But each speaker of a language has something in his/her head that constitutes the person's knowledge of that language. (And let's not get bogged down here in whether this is "knowing that" or "knowing how"Ryle, 1949.) I have heard a linguist avoid the loaded word "competence" in favor of the circumlocution, "permanent memorial representations," but there is no distinction here, outside the politics of the subject. Competence exists as one phase in the life cycle of a language. Competence in a language is acquired by exposure to performance data. Give a child Cantonese performance data, and the child acquires Cantonese competence; Ashanti leads to Ashanti, Dutch to Dutch. Performance (plus the innate biases) causes competence. Equally clearly, competence shapes performance, as emphasized above. The life cycle of a language is [performance $>$ competence $>$ performance $>$ competence $>$ performance $>$ competence] for as long as there are speakers. At the level of our discussion here, the alternative terms, I-language and E-language, are just as apt. E-language begets I-language, which begets E-language, and so on. The situation is complicated by many factors, including language contact, learning from one's peers as well as one's parents, and so on. But the two-phase nature of the life cycle of a language is well accepted by modern historical linguistics (Andersen, 1973; Kroch, 2000; Lightfoot, 1999).

The two-phase existence of languages has typically not been widely applied to explaining universals of language (but see Chapter 4 and references there). Much more common has been the stand-alone story, "Internalized competence grammars have the properties they have because children are innately disposed to acquire grammars with those properties." We need to augment this story with another: "Performance in a language has the properties it has because speakers are disposed to produce utterances with those properties." Obviously part of the relevant disposition is the speaker's competence in the language. But that is not all. The form of an utterance in context is chosen as a function of the proposition the speaker wishes to convey, the speaker's attitude to this proposition, and the speaker's assumptions about what the hearer already knows, to name the foremost factors. The morphosyntactic form having been chosen, further performance factors affect the phonetic form of the utterance, which might be subject to truncation, slurring, and so forth. Some of these factors are so common in human discourse that something systematic can be said about them. Performance is not all random noise, beyond the reach of systematic study. The style of study of how performance factors affect the shape of 
utterances is necessarily quite different from the typical logiclike formalizing style of syntactic theory. The study of performance involves, for example, (1) statistical issues of frequency, such as figure widely in sociolinguistics, for example, in the articles appearing in the journal Language Variation and Change and much work by William Labov and his collaborators (e.g., Labov, 2000), and (2) quantitative measurement along continuous dimensions, as in work relating phonetic performance to phonological competence (e.g., Ohala, 2005). The phenomenon of frequency brings us back to an explanation of the universality of irregularities in language.

The irregular forms in a language tend strongly to include the most frequent lexical items. This is certainly true of English verbs, for instance. An obvious model for explaining the universal frequency-irregularity correlation involves random performance modification of the pronunciation of words. Modified versions of the frequent words (e.g., haved > had) will be heard relatively frequently in discourse, giving the child learner a chance to acquire these forms by rote. Other less frequent forms may not always be exemplified in all their paradigm slots in the experience of the child, and the child, having heard no exemplar, will apply regular rules to produce the forms missing from its experience. This process has been computationally modelled by Hare and Elman (1995) and by Kirby (2001).

Languages universally maintain at least a certain minimal level of complexity. Although no accepted measure of linguistic complexity exists, it is clear that languages differ in the complexity of their various subsystems. Some languages have complex case systems, others have none; some languages have complex noun class systems, others have none; some languages have complex tense/aspect morphology, others have none. It has been an article of faith among linguists that every language is roughly equally complex, overall. Edward Sapir expressed it thus: "We know of no people that is not possessed of a fully developed language. The lowliest South African Bushman speaks in the forms of a rich symbolic system that is in essence perfectly comparable to the speech of the cultivated Frenchman." (Sapir, 1921, p. 22) Interestingly, though, in the sentence immediately before his oft-quoted aphorism about Plato walking with the Macedonian swineherd, Sapir writes that "both simple and complex types of language of an indefinite number of varieties may be found spoken at any desired level of cultural advance" (Sapir, 1921, p. 219); so here at least he seemed to envisage the possibility of "both simple and complex types of language."

The doctrine that every language is equally complex may be too extreme. For example, David Gil claims that Riau Indonesian is in its basic grammatical organization simpler than linguists have typically been willing to admit of any language (Gil, 2001). And it looks as if the Amazonian language Piraha is overall simpler than many other familiar languages (Everett, 2005). But even Piraha maintains a high level of morphological complexity; it is clearly a human language, orders of 
magnitude more complex than anything a nonhuman could master. What keeps languages, universally, up to a minimal level of complexity?

Computational experiments in simulating the competence $>$ performance $>$ competence] cycle in the life of a language have shown that in order for a language not to collapse to an extreme simple state there needs to be some counterpressure to the generalizing and simplifying tendency built into acquisition. In one illustrative simulation (Teal \& Taylor, 2000), computational agents learned finite state grammars from sets of strings presented to them, arriving at their preferred grammars on the basis of minimal description length (MDL). MDL-style acquisition values statistically salient generalizations, which hold over the input data. Once a generation of agents had acquired grammars in this way (from an initial hand seeded set of data), they in turn produced sentences consistent with their grammars for the benefit of the next generation of agent learners. And so it went on, for many generations. Note two things: this implements the [competence $>$ performance $>$ competence $>$ performance] life cycle discussed above; and the simulated agents are only acquiring grammars defining sets of well-formed strings - no simulation of meaning is involved. The results show a steady downhill decrease in complexity of the grammars acquired by successive generations. This is typical of experiments in which the only activity of the learning agents is the construction of the simplest possible grammars accounting for the utterances observed. There is a hill-climbing effect whereby, over generations, languages, and their grammars become ever simpler, and in the limit would arrive at extreme simplicity, for instance, a one-sentence language. Language acquisition tends to reduce the entropy of the language generated by the acquired grammar relative to the entropy of the input corpus.

Pointing in exactly the same direction are computational simulations of the evolution of vowel systems, most prominently by de Boer (2001). The most common vowel system in languages is the five-vowel symmetrical $\{\mathrm{i}, \mathrm{e}, \mathrm{a}, \mathrm{o}, \mathrm{u}\}$ system. Other systems exist, but the common five-vowel system seems to be the one that strikes the optimal compromise between simplicity and the need to preserve distinctions. De Boer's model arrives at a distribution of vowel systems that is statistically very similar to the overall distribution of vowel systems in the world's languages. His system incorporates the cycle of learning and production discussed above, with one generation learning an internalized system from the products output by the previous generation. The model explicitly incorporates a mechanism occasionally injecting a new random vowel into the systems of his agents. If this mechanism were not present, the evolved systems would tend to collapse, over time, to a single vowel, due to the (realistic) presence of noise in the system, which allows vowels to wander through the vowel space, and the possibility of merger between originally distinct vowels when they get close to one another. Vowel merger is a simplification process in acquisition. 
So why aren't languages maximally simple, comprising just one sentence, and having just one vowel? If diachronic simplification, of which the engine is generalizing induction by learners, were the only pressure acting on languages, we would expect them to collapse. Of course they don't, and we all know why. Languages are used to communicate a rich set of distinct meanings. Humans need all those different sentences to say the things they want to say. And we need a minimal number of vowels so that we can shorten sentence length, while still maintaining an acceptable level of semantic expressivity. All this is obvious. But it is nowhere built into theories of language universals based on properties of the language acquisition device. Emphasis on formal universals de-emphasizes semantic content. How do languages manage to stay so good for communication?

Innate learning biases can explain some universals of language. Learning is one process mediating the transitions between life phases in the history of a language. Learning extracts from input data, in the form of utterances in context, an internalized representation of the language system. But another process, production, uses the internalized system representation to give out utterances in context. Production starts with having something very specific that you want to express clearly in such a way that your specific meaning is likely to be understood by your hearer. Humans apparently have extremely rich conceptual/intentional systems, providing them with elaborate, subtly distinguished thoughts that they express in language. The most striking universal of language, often overlooked in the forest of technical detail, is the enormous communicative expressivity of languages. Learning, incorporating generalizations about the data observed, is a centripetal force in the history of languages, tending to reduce complexity. Production is the counterbalancing centrifugal force, tending to maintain and even increase complexity. Note the essential part played by production in the explanation of the universal frequency-irregularity correlation discussed earlier; in this case, speakers relax on considerations of distinctness and let economy of effort in production take precedence.

There is a general comprehension/production asymmetry observed both in acquisition (where production is typically behind comprehension) and adult processing (where people in general have wider comprehension abilities compared to what they actually produce). This may perhaps be a clue to the proportions of the influence that acquisition and production have on the maintenance and development of languages. But it is clear that without some effort to produce utterances clearly distinguished by their phonetic and grammatical structure, languages would not sustain the level of complexity that they do. In the effort to produce clearly differentiated utterances, some a priori biases must also operate, perhaps domain-specific to language, but perhaps dependent on factors not specific to language, such as natural ways of guiding the attention of others to a desired topic of conversation. 


\subsection{Languages Evolve Along Universal Paths}

Consider Jakobson's famous Kindersprache, Aphasie und allgemeine Lautgesetze (Jakobson, 1941). All three elements in the original German title denote diachronic processes, the development of language in children, the loss of language in aphasics, and general sound laws. Sound laws, when Jakobson wrote, were universally understood as historical. Thus Grimm's Law is a sound law, describing a historical change in Germanic. But the linguistic intellectual climate of the second half of the twentieth century was dominated by synchrony when the quest for universals began to take center stage. And allgemeine Lautgesetze, accordingly, got fashionably rendered as phonological universals in the 1968 translation. The correspondence that Jakobson pointed out had a massively useful impact on the field, but the subtle mistranslation of allgemeine Lautgesetze as phonological universals steered explanation of universals away from a connection with diachronic language change. Jakobson's own discussion of sound laws in the book is for the most part stolidly synchronic, with Chapter 14, for example, being entitled (in the here faithful English translation) "Identical Laws of Solidarity in the Phonological Development of Child Language and in the Synchrony of the Languages of the World." A factor that probably deterred even Jakobson from making too much of the connection with the history of languages was the prevalent (and still prevalent) commitment to uniformitarianism, the idea that earlier stages of languages were just as complex as modern languages. It was acceptable to state that children start with a minimal consonant set, such as $\{\mathrm{m}, \mathrm{p}, \mathrm{t}\}$, far smaller than found in any extant language, and that aphasic speech could degenerate to this minimum, but it was not so acceptable to speculate about "primitive" prior historical stages of languages. Nevertheless, in a few short passages, Jakobson does allow himself to speculate about "glottogony" (now sometimes called "glossogeny") and to refer to the "origin of language" once in a brief one-paragraph chapter. He articulates the "principle of language change" thus: "This principle is simple to the point of being trivial; one cannot erect the superstructure without having provided the foundation, nor can one remove the foundation without having removed the superstructure" (p. 93). Amen to that.

If one is seriously interested in the origins and evolution of the language faculty and of individual languages, it seems inescapable that languages had humble beginnings. Language, as Hockett (1978) put it, did not spring fully formed from Jove's brow. The [competence $>$ performance $>$ competence $>$ performance] framework outlined in the previous section provides a dynamic essentially different from Darwinian natural selection. In biological evolution, there is no equivalent to the continuing zigzag between E-language and I-language; genotypes beget genotypes directly, and DNA is copied into more DNA. Thus, while still noting very general parallels between biological evolution and linguistic evolution (glottogony/glossogeny), as 
nineteenth-century theorists such as Schleicher (1873) did, we can envisage a framework for the evolution of languages in which Jakobson's parallel between child language and glottogony/glossogeny fits very naturally. Languages evolve along the paths they follow because they are learned by children following these same paths, and because children, having acquired a "foundation" on the basis of learning from exemplars of their parents, have the opportunity, when it comes to producing messages themselves, to invent some additional "superstructure" (to adopt Jakobson's terms). Not too much should be made of the term invent here. I use invention in the sense in which elements of Creole languages can be "invented" by the first generation of speakers on the basis of a pidgin. A spectacular case of such invention, in Nicaraguan Sign Language, has recently been extensively documented (Kegl, 2002; Kegl \& Iwata, 1989; Kegl, Senghas, \& Coppola, 1999; Senghas, 1995a, 1995b, 2001, 2003). Beyond creolization, linguistic invention is spontaneous and very small in scale, like stretching the syntactic context of a verb beyond its previous limits, as children do, or starting to make a previously allophonic variation into a phonemic distinction, or using a word in a new metaphorical way. Inventions such as these are manifest in production. Some invention can also happily come under the heading "reanalysis" of the input data, whereas some invention genuinely stretch the boundaries of the language. Invention is a special, atypical form of acquisition, adding new structures to a language, assuming the inventive speaker learns from his/her own inventive performance by adding the new usage to the person's repertoire.

Individual languages evolve along lines very similar to the development of language in children. The accumulation of ontogeny over generations creates glossogeny. This idea is actually not so very different from the modern standard nativist explanation of language universals, which holds that languages have the properties they have because children are innately disposed to acquire languages with just such properties. The only difference is that the theory proposed here hypothesizes that languages may take a long stretch in their history to take on the forms indicated by innate dispositions. There can be, in a technical sense, immature subsystems of languages. Languages in their synchronic patterns exhibit "growth rings," layering of structure showing what stages they have evolved through. Universally, languages are subject to historical growth (and shrinkage). Not surprisingly, languages preserve signs of growth. Many of Greenberg's synchronically stated implicational universals can be interpreted in this way. And interpreting them in this way begins to show an explanation of why they should be true. (Of course, the quest for explanations is never ending; today's explanans is tomorrow's explanandum.) I will mention a few of Greenberg's original universals and discuss them in this light.

Greenberg's Universal 34 states, "No language has a trial number unless it has a dual. No language has a dual unless it has a plural" (Greenberg, 1963). We can 
correlate this with a hypothesis about ontogeny: "No child can acquire a trial number unless it has already acquired a dual. No child can acquire a dual unless it has already acquired a plural." Next, here is a phonological universal: "If a language has VCC syllable rhymes, it has VC syllable rhymes; if it has VC syllable rhymes, it has V syllable rhymes," which generates the hypothesis, "A child can only acquire VCC syllable rhymes it if has already acquired VC syllable rhymes; it can only acquire VC syllable rhymes if it has already acquired V syllable rhymes." In general, we may advance the following hypothesis about a correlation between universals and ontogeny: "Given a universal, 'If a language has X, it always has Y,' then X cannot be acquired unless $\mathrm{Y}$ has been acquired first." All this is pretty much pure Jakobson.

Here is a case that needs a little more discussion: Greenberg's Universal 29 states, "If a language has inflection, it always has derivation" (Greenberg, 1963). Translating this according to the formula proposed, we get, "A child cannot acquire inflection unless it has already acquired derivation." At first glance, this is false; children can acquire productive plural inflections and apply them to derived forms such as statement before they are able to productively derive a noun from a verb by suffixing -ment. In fact, however, no English speaker can productively derive a noun from a verb by suffixing - ment. Try it, as a thought experiment, with arrive or kill to give *arrivement and *killment,- -it doesn't work. So the sense in which a language "has" derivation is different from the sense in which a language has inflection. Inflection is a generally productive process, reflecting an internalized rule. Derivation is a sporadic historical process resulting from nonce invention by individuals, which just happen to "stick." Derived forms are learned by rote by children. After some education, people develop some metalinguistic awareness and can contemplate the hypothetical productive application of derivational processes, as I just did with *arrivement and *killment. It is obviously the case that no child can apply the plural inflection to a derived noun unless he or she has already acquired that derived singular form. In this limited sense, then, the correlation between universals and ontogeny holds in this case, too.

My argument in the previous paragraph does not relate, however, to the sense in which Greenberg intended his Universal 29. That argument involved processes of derivation and inflection as applied to the same stem (e.g., statements, denationalizes). But Greenberg was motivated by the following more general consideration: "There are probably no languages without either compounding, affixing, or both. In other words, there are probably no purely isolating languages. There are a considerable number of languages without inflections, perhaps none without compounding and derivation" (Greenberg, 1963). It can be clearly shown that much derivation is a historical process; I will give examples immediately below. Thus, this last statement of Greenberg gives credence to the claim that, in respect of their derivational morphology at least, all languages are the products of historical processes. 
Structured derivational morphology can be clearly related to the idea of growth rings, layered traces of the historical development of a language. As an example, a search in the Oxford English Dictionary for the earliest recorded forms of the word nation and its derivatives shows the following pattern:

nation 1300

national 1597

nationally 1649, nationality 1691, nationalist 1715 ,

nationalize 1800, nationalism 1836

denationalize 1807, nationalization 1813, nationalizer 1883

denationalization 1814

The levels of indentation here show the degree of morphological complexity - the number of morphemes in each word. Clearly, words were derived and added to the language in historical sequence. The layers in the synchronic forms are like geological strata, reflecting phases of invention back in the past. Thousands more such examples can be found.

The idea of layers of structure reflecting previous stages of the language is not new. Hopper gives a good example:

Within a broad functional domain, new layers are continually emerging. As this happens, the older layers are not necessarily discarded, but may remain to coexist with and interact with the newer layers.

(Hopper, 1991, p. 22)
a. Periphrasis: We have used it (newest layer)
b. Affixation: I admired it (older layer)
c. Ablaut: They sang (oldest layer) (ibid 24)

Thus, in the oldest layer, it is not possible to isolate a single morpheme indicating past tense; it would be very implausible to claim that the stem of the word is the discontinuous shell, $s-n g$, and that the inserted - $a$ - vowel is a "past tense morpheme." Much Proto-Indo-European verbal morphology was like this, and vestiges survive in the strong verbs of the Germanic languages. Affixation by a productive past tense morpheme-ed, as in admired, is historically older than the periphrastic construction seen in have used, where free-standing words are syntactically strung together. All three ways of expressing pastness (with a subtle semantic difference between the last two) are present in Modern English, but they date from different eras. In this way, a language is like an ancient city, with buildings dating from different historical periods, but all still functioning.

The general unidirectionality of grammaticalization suggested by writers such as Hopper and Traugott (1993) indicates an incremental growth in the complexity 
of languages, and it follows from Jakobson's "trivial" principle that the foundations must precede the superstructure (quoted above), that implicational universals have a diachronic explanation. This does not deny that language acquisition plays a role; rather it acknowledges the crucial role that acquisition plays in explaining linguistic universals, but stretches out its application over successive generations in the history of languages. This view of how languages get to be the way they are is also in complete conformity with what we know about how cultural institutions in general grow.

Wrapping up, this chapter has chosen to take the goal of linguistics to be an explanation of how whole languages get to be the way they are. Other scholars are free to choose a narrower goal, such as discerning the contribution made by innate individual psychological biases in determining the shape of languages. But more narrowly circumscribed goals also run the risk of blinkered vision, and one may too easily assume that the factor whose contribution one is investigating is the only significant factor involved, or that other possible factors are either trivial or too complex to study systematically. I have tried to show that we can gain some insight into the forces shaping languages by considering them as products of a historical spiral involving both acquisition and production, learning and speaking, and occasionally innovating, over many generations.

\section{Key Further Readings}

Bybee (2006) provides an extended version of her Presidential Address given to the Linguistic Society of America in January 2005: "The impact of use on representation: grammar is usage and usage is grammar." The rhetoric in the title, suggesting a literal equivalence between grammar (for which I have accepted the term "competence") and usage (for which I have accepted the term "performance") is unfortunate. In the article itself, however, the rhetoric is modified to represent a view very similar to the two-phase cycle in the existence of languages that I have espoused in this essay. Joan Bybee has been a prominent exponent of this view.

Heine and Kuteva (2002) dare to go against the prevailing uniformitarianism and suggest that earlier forms of languages had much simpler inventories of grammatical categories than many modern languages, drawing on evidence from grammaticalization. Hopper and Traugott (1993) is a major source setting out the idea of incremental language growth leaving traces in the history of a language. Jakobson (1941) is a classic, readable book, setting the scene for the ideas set out here. Of my own work: Hurford (1991) sets out the basic idea of the life cycle of languages advocated in this chapter; Hurford (2002) surveys computational models implementing the idea of language evolution through a life cycle of learning and production. 
52 Language Universals

References

Andersen, H. (1973). Abductive and deductive change. Language, 49, 765-793.

de Boer, B. (2001). The origins of vowel systems. Oxford: Oxford University Press.

Bybee, J. (2006). From usage to grammar: the mind's response to repetition. Language, 82 , $711-733$.

Chomsky, N. (1965) Aspects of the theory of syntax. Cambridge, MA: MIT Press.

Chomsky, N.(1981). Lectures on government and binding. Dordrecht, Holland: Foris Publications.

Chomsky, N. (1986). Knowledge of language: Its nature, origin and use. New York: Praeger.

Everett, D. (2005). Cultural constraints on grammar and cognition in Piraha: Another look at the design features of human language. Current Anthropology, 46(4), 621-646.

Gil, D. (2001). Creoles, complexity and Riau Indonesian. Linguistic Typology, 5, 325-371.

Greenberg, J. (1963). Some universals of grammar with particular reference to the order of meaningful elements. In J. H. Greenberg (Ed.), Universals of language (pp. 73-113). London: MIT Press.

Hare, M., \& Elman, J. L. (1995). Learning and morphological change. Cognition, 56(1), 61-98.

Hauser, M., Chomsky, N., \& Fitch, T. (2002) The faculty of language: What is it, who has it, and how did it evolve? Science, 298, 1569-1579.

Heine, B., \& Kuteva, T. (2002). On the evolution of grammatical forms. In A. Wray (Ed.), The transition to language (pp. 376-397). Oxford: Oxford University Press.

Hockett, C. F. (1978). In search of Jove's brow. American Speech, 53, 243-313.

Hopper, P. J. (1991). On some principles of grammaticization. In E. C.Traugott \& B. Heine (Eds.), Approaches to grammaticalization (Vol. 1, pp. 17-35). Amsterdam: John Benjamins.

Hopper, P. J., \& Traugott, E. C. (1993). Grammaticalization. Cambridge: Cambridge University Press.

Hurford, J. R. (1991). Nativist and functional explanations in language acquisition. In I. Roca (Ed.), Logical issues in language acquisition (pp. 85-136). Holland: Foris Publications.

Hurford, J. R. (2002). Expression/induction models of language evolution: Dimensions and issues. In T. Briscoe (Ed.), Linguistic evolution through language acquisition: Formal and computational models (pp.301-344). Cambridge: Cambridge University Press.

Jakobson, R. (1941). Kindersprache, Aphasie und allgemeine Lautgesetze. Uppsala: Almqvist \& Wiksell. Translated as Child language, aphasia and phonological universals by A. R. Keiler, 1968. The Hague: Mouton.

Kegl, J. (2002). Language emergence in a language-ready brain: Acquisition issues. In C. Morgan \& B. Woll (Eds.), Language acquisition in signed languages (pp. 207-254). Cambridge: Cambridge University Press.

Kegl, J., \& Iwata, G. A. (1989). Lenguaje de Signos Nicaraguense: A pidgin sheds light on the “creole?” ASL. In R. Carlson, S. DeLancey, S. Gildea, D. Payne, \& A. Saxena (Eds.), Proceedings of the fourth meeting of the Pacific Linguistics Conference (pp. 266-294). Eugene, OR: University of Oregon.

Kegl, J., Senghas, A., \& Coppola, M. (1999). Creation through contact: Sign language emergence and sign language change in Nicaragua. In M. DeGraff (Ed.), Language creation and language change (pp. 179-237). Cambridge, MA: MIT Press. 
Kirby, S. (2001). Spontaneous evolution of linguistic structure: An iterated learning model of the emergence of regularity and irregularity. IEEE Transactions on Evolutionary Computation, 5(2), 102-110.

Kroch, A. (2000). Syntactic change. In M. Baltin \& C. Collins (Eds.), Handbook of contemporary syntactic theory (pp. 629-739). Malden, MA: Blackwell.

Labov, W. (2000). Principles of linguistic change. Volume II: Social factors. Oxford: Blackwell.

Lightfoot, D. (1999). The development of language. Oxford: Blackwell.

Ohala, J. (2005). Phonetic explanations for sound patterns: Implications for grammars of competence. In W. J. Hardcastle \& J. M. Beck (Eds.), A figure of speech. A Festschrift for John Laver (pp. 23-38). London: Erlbaum.

Ryle, G. (1949). The concept of mind. London: Hutchinson.

Sapir, E. (1921). Language: An introduction to the study of speech. New York: Harcourt, Brace \& Worlfd Inc.

Schleicher, A. (1873). Die Darwinsche Theorie und die Sprachwissenschaft. Weimar: H. Böhlau.

Senghas, A. (1995a) Children's contribution to the birth of Nicaraguan sign language. Ph.D. thesis, MIT.

Senghas, A. (1995b). The development of Nicaraguan Sign Language via the language acquisition process. In D. MacLaughlin \& S. McEwen (Eds.), Proceedings of the Boston conference on language development (Vol. 19, pp. 534-552). Boston: Cascadilla Press.

Senghas, A. (2001). Children creating language: How Nicaraguan Sign Language acquired a spatial grammar. Psychological Science, 12(4), 323-328.

Senghas, A. (2003). Intergenerational influence and ontogenetic development in the emergence of spatial grammar in Nicaraguan Sign Language. Cognitive Development, 18, 511-531.

Teal, T. K., \& Taylor, C. E. (2000). Effects of compression on language evolution. Artificial Life, 6(2), 129-143. 